\title{
Museus Locais: Fronteiras Reais e Imaginárias ${ }^{1}$
}

Prof. Doutora Judite Primo ${ }^{2}$

\begin{abstract}
Resumo:
O nosso enfoque será para sinalizar uma possível compreensão do que representa o museu da e na contemporaneidade. Quer se trate de museus tradicionais, quer se trate de museus locais que se reconhecem no cerne da Sociomuseologia, encontraremos sempre a ideia de patrimonialização, de cenarização, de teatralização, de apresentação pública de bens culturais, de processos educativos mais ou menos formais. Encontraremos também a socialização das referências de património e memória coletiva, no contexto do território de grupos sociais determinados, que dão forma à lógica própria dos museus entendidos e assumidos como narradores.
\end{abstract}

Palavra-chave: Sociomuseologia; teatralização; memória colectiva.

\begin{abstract}
:
Our focus will be to indicate a possible understanding of what is a contemporary museum. Whether it's traditional museum, whether a local museum recognized at the heart of Sociomuseology we always find the idea of patrimonialization of theatricality, public presentation of cultural goods, more or less formal educational processes. Wr also find the socialization of heritage references and collective memory, in the context of the territory of certain social groups, that give shape the very logic of museums understood and assumed as storytellers and intervenors.
\end{abstract}

Key words: Sociomuseology; theatricality; collective memory.

\footnotetext{
${ }^{1}$ Este texto tem por base as reflexões tratadas na tese de doutoramento «A Museologia e as Políticas Culturais Europeias: O Caso Português.», defendida em Abril de 2007 na Universidade Portucalense - Porto - Portugal.

2 Doutora em Educação e Políticas Culturais, Mestre em Museologia e Directora do Doutoramento em Museologia da ULHT - Lisboa.

E-mail: judite.primo@ulusofona.pt
} 


\section{PONTO DE PARTIDA}

Hoje pretendemos articular algumas ideias com a intenção de compreender melhor a relação entre a ideia de museu e o contexto sociopolítico que lhe deu forma a partir da segunda metade do séc. XX. Falámos de um movimento internacional criador de diferentes tipologias de museus e de ação museológica, comprometidos com a dinâmica sociocultural local e compreendendo a importância global da sua interferência.

No entanto não nos parece possível falar da ideia de museus sem evocarmos igualmente a construção das noções de património, articuladas com a criação do Estado-Nação Moderno e da sua relação com a expansão colonial. Teremos então que evocar alguns aspetos que marcaram a construção do museu moderno.

Evidente, que o nosso enfoque será para sinalizar uma possível compreensão do que representa o museu da e na contemporaneidade. Quer se trate de museus tradicionais, quer se trate de museus locais que se reconhecem no cerne da Sociomuseologia, encontraremos sempre a ideia de patrimonialização, de cenarização, de teatralização, de apresentação pública de bens culturais, de processos educativos mais ou menos formais. Encontraremos também a socialização das referências de património e memória coletiva, no contexto do território de grupos sociais determinados, que dão forma à lógica própria dos museus entendidos e assumidos como narradores. 
No contexto mais amplo dos processos contemporâneos de globalização a atuação dos museus confronta-se com as questões de hibridação cultural e de novas lógicas do que hoje podemos entender por comunidade e /ou construção de novas territorialidades (de acordo com alguns dos autores consagrados das Ciência Sociais, como Baumam, Castells e Boaventura). Por isso evocaremos os diferentes, porém complementares, processos de urbanização, de massificação da cultura, educativos, culturais, migratórios e de transnacionalização de bens materiais e simbólicos.

\section{A LEGITIMAÇÃO PÚBlicA dOS MUSEUS E DOS PATRIMÓNIOS.}

A construção da ideia de Nação, nos séculos XVIII e XIX, envolvendo por um lado a referência a um passado mais ou menos mítico, assentava num novo entendimento e lugar que as ideias de língua, de etnicidade ou de tradição, entre outras, assumiam na época.

Todas essas ideias manifestavam-se de forma material através de objectos herdados ou ideias passíveis de serem materializadas, constituindo-se no que poderíamos denominar por entendimento moderno da ideia de património enquanto manifestação identitária. Esse novo olhar sobre o património deu-se por referência ao passado, mas também, por necessidade de estabelecer as diferenças numa Europa de Nações, paralela à Europa da expansão colonial.

Este processo de construção da noção de património seguiu dois caminhos que se entrecruzavam: o desenvolvimento da ciência, fundamentado nos estudos de novas disciplinas (entre outras como a etnografia, paleontologia, da historiografia 
moderna, arqueologia) e o caminho da criação de palcos cenários, museus, arquivos e bibliotecas no Estado-Nação e que tinha o objetivo político de institucionalizar a memória. Assim nasce o Museu Público!!

Da mesma forma que o Estado-Nação propunha olhar o mundo através das enciclopédias, no campus patrimonial e museológico, o mesmo Estado-Nação, impunha esta dupla atitude: classificatória e de institucionalização da memória, por meio do uso das coleções reunidas desde o Renascimento e sua transformação em acervos dos primeiros museus públicos. Os museus cumpriam a função de construção de códigos comuns que pudessem ser partilhados por todos os elementos de uma sociedade sem distinção de grupos etários, económicos e sociais. A utilização do museu como instrumento público, deve-se ao facto deste servir como um grande palco para a apresentação desses códigos, criados para alimentar a ideia do nacional por oposição ao não nacional, por oposição a ideia do "outro".

Na primeira metade do séc. XIX a instalação de museus públicos era marcada pela mistura de conceitos que vão desde a ideia de contemplação, de templo de saber, de espaço disciplinador, espaço educativo, ou ainda como representante do carácter nacional. Sob a égide do nacionalismo foram criados a esmagadora maioria dos museus públicos na Europa oitocentista. A arte, arqueologia, história e etnografia eram entendidas como disciplinas essenciais a serem trabalhadas numa nação moderna e para que a sua divulgação pudesse ser mais expressiva discutiase de que forma os museus públicos poderiam servir de fomento e veículo pedagógico destas disciplinas.

Os museus da Modernidade estiveram ligados à ideia de construção do nacional, e referência de memória que fomentava 
a construção de um novo quadro social. O interesse cultural e científico em relação às colecções converte as instituições em instrumentos indispensáveis de investigação científica, ideia que se concretiza e se reforça ao longo do século XX.

\section{A CONSTRUÇÃO DO MUSEU CONTEMPORÂNEO}

Tradicionalmente o museu chegou ao século XX como um testemunho que se pretendia fiel a realidade, ou testemunho de uma realidade imaginada. Para a generalidade das instituições assim definidas, a sua maior virtude era oferecer aos visitantes a totalidade das culturas de uma nação.

$\mathrm{Na}$ segunda metade do séc. XX alguns movimentos alteraram essa dinâmica. De um lado, a emergência dos processos globalizantes que romperam com as delimitações dos Estados-nação, de outro lado, a democratização da educação formal e do conhecimento que possibilitaram o surgimento dos movimentos sociais, que constataram o fracasso do projeto civilizatório e humanista da Modernidade.

No campo museal, novas referências patrimoniais e diferentes compreensões sobre o lugar e o papel das memórias sustentam o aparecimento de novos modelos de museus e de práticas sociomuseológicas. Os novos modelos de museus podem ser identificados como aqueles que buscavam, no alargamento da noção de património, o reconhecimento das identidades coletivas locais e o empoderamento das comunidades que ganham voz na escolha e tratamento das suas referências patrimoniais. Esses novos museus têm vindo progressivamente a estimular a colectividade na valorização e descodificação dos seus patrimónios e das suas memórias colectivas. 
Os novos museus, que têm por função primária o desenvolvimento sustentado das comunidades locais por meio dos trabalhos com o património, tentando romper com a noção do passado como algo estanque e sem vinculação directa com o presente, passando a assegurar procedimentos etnológicos na transmissão dos saberes, das habilidades e do saber fazer.

A questão fundamental no campo da memória colectiva e do seu tratamento pela Museologia é de reconhecermos que ela corresponde apenas a uma maneira possível, dentre outras, de estabelecer espaços de organização e de evocação das referências culturais colectivas ao serviço do conhecimento e desenvolvimento sustentado de sistemas de administração da memória.

O museu foi-se transformando, nas últimas décadas do século $X X$, num centro de expressão da dinâmica social dos grupos que trabalhavam a partir da memória e das referências do passado para a construção das suas identidades locais.

A partir do final dos anos 60 do século XX os modos de pensar, de fazer e de saber, para além dos edifícios, obras de arte e objetos raros, se tornaram objetos da investigação e do fazer museológico. A Nova Museologia, do ponto de vista dos princípios, não se conduz pela exaltação aos objetos, a conservar ou a exibir a um público, mas sim pela valorização dos saberes e fazeres dos sujeitos sociais. Com estes novos princípios o museu foi-se transformando num centro de expressão da dinâmica social dos grupos que trabalhavam a partir da memória e das referências do passado para a construção da sua identidade.

Todo esse conjunto de novas ideias traduziu o modo pelo qual o social se tornou objeto privilegiado da ação cultural e museológica. Segundo Jean Pierre Jeudy: "Museologia $e$ 
educação popular legitimam-se por sua vez demonstrando o drama do deslocamento do tecido social, da desintegração dos corpos sociais no decorrer das transformações recentes das sociedades." (Jeudy, 1990, p.32).

A ideia de um novo tipo de museu, mais socializador e dialógico, tornou-se incómoda porque isso implicava abolir ativa e continuamente os desvios entre a realidade económica e tecnológica e a maneira de pensar e viver essa realidade. 0 trabalho social ganha nova perspectiva quando se investiu na memória do social. A Sociomuseologia convocava os sujeitos sociais a intervirem ativamente e a resistirem aos determinismos da História dos heróis e do passado glorioso que exclui os seus conhecimentos e as suas compreensões sobre o mundo.

No campo museal, onde a valorização do social se mostra como forma de supressão de "traumas e recalques culturais», as memórias do social são utilizadas numa perspectiva de transformação de toda a vida presente. Não se trata mais da sistematização estritamente técnica da cultura. Pesquisas e exposições são realizadas a partir do objectivo de tornar actual a vida social, sem perder as suas referências culturais. O social passa então a ser priorizado em relação aos conteúdos materiais dos museus, às metodologias de trabalho e seus destinatários e/ou participantes do processo museológico.

O novo museu, nas suas diferentes formas e tipologias, ao trabalhar com o social pretende responder aos dilaceramentos da vida cultural e social. O social é então totalmente reinvestido na vida das comunidades, tornando-se o objeto das ações culturais.

Não importa discutir o quanto o museu tradicional, consciente ou inconscientemente, produz e afirma a ordem 
estabelecida do presente. Importa, isso sim, reconhecê-lo como um aparato ideológico do Estado com funções legitimadoras para proporcionarem diferentes usos da cultura. No entanto, é importante reconhecer um outro movimento museológico que segue o caminho do contra-poder, onde mais que buscar legitimar a ordem estabelecida, busca questionar sobre a memória social e os processos de patrimonialização, tornando-se também em instrumento que permite aos seus atores negociarem e articularem, de forma consciente, uma nova relação com o passado.

\section{NOVAS TERRITORIALIDADE}

Os "movimentos sociais em contextos urbanos», nas últimas décadas do século $\mathrm{XX}$, com seus discursos, atores e organizações, têm vindo a ser integrados, direta ou indiretamente, nas estruturas dos governos locais.

A partir das transformações do mundo contemporâneo resultantes dos processos de urbanização, industrialização e massificação da cultura, migrações e transnacionalização dos bens (materiais e simbólicos), a globalização e as formas de integração económica, exigiram uma redefinição do conceito de nação. A contemporaneidade e seus contextos pressupõem que as populações consumam informações, entretenimento e alimentos oriundos do estrangeiro; por outro lado os processos migratórios actuais demonstram que grande parte das populações que residem fora das suas fronteiras de origem, reproduz no exterior a chamada «cultura nacional» buscando assim manter relações com o seu País de origem. Ao mesmo tempo que a comunicação de massa dos médias (rádio, televisão, Internet) funciona para trazer, ao consumo interno, informações 
e códigos de outros povos e de outros territórios, também funcionam como recursos para a documentação e difusão da própria cultura para além das comunidades locais que a geraram.

Os valores nacionais veiculados pelos médias são, por vezes, tão importantes e significativos quanto os bens tradicionais, sobretudo se levarmos em conta o seu importante papel em relação à música, ao cinema e à TV na consagração, socialização e renovação de alguns comportamentos.

Ficamos assim, no contexto dos museus locais e museus da Sociomuseologia, com o desafio de entendermos o património cultural e as referências de memória coletiva de acordo com as condições históricas, sociais, económicas e comunicacionais da contemporaneidade e trabalha-las numa lógica completamente diferente da lógica que formatou os primeiros museus da modernidade.

\section{EM TOM DE CONCLUSÃO}

É neste contexto que se coloca actualmente o lugar dos museus e da museologia, num quadro social e económico em profunda transformação. Não somente pelas indefinições socioeconómicas, mas sobretudo numa tentativa de compreender as diferentes dimensões da globalização, da homogeneização das culturas e da desterritorialização.

Neste novo panorama a Sociomuseologia, enfrentou e enfrenta múltiplos e diferentes desafios; desafios que se prendem com a alteração do panorama da museologia no contexto internacional e nacional, onde se entrecruzam diferentes noções, conceitos e objetivos. O desafio da Sociomuseologia é certamente o de contribuir para a compreensão desta nova realidade museológica, assente na existência de museus que se afirmam pela 
utilização simultânea de diferentes conceitos, tornando-se assim numa nova categoria que poderíamos denominar de Museus Complexos. $^{3}$ A Sociomuseologia como área de ensino, de investigação e de prática social tem vindo nos últimos 20 anos a consolidar-se como uma área de conhecimento, no seio das ciências sociais.

Desta forma, já não mais podemos pensar nos museus por meio das categorias criadas anteriormente pela modernidade, que organizava e classificava o mundo por meio das especificidades disciplinares, mas e de acordo com Mário Moutinho, mesmo correndo o risco de omissão que qualquer sistematização implica, agrupar os museus contemporâneos em 4 diferentes categorias.

1-Museus tradicionais de objetos, que agora desenvolvem novas tecnologias de apresentação e que exigem competências específicas centradas no público visitante. Mas também museus modernos que se adaptam as exigências dos públicos,

2-Museus de comunidade "formais" centrados em novos processos de comunicação e organização, com recursos ou não a novas tecnologias de comunicação mas orientados sobretudo para o desenvolvimento social. São os museus da nova museologia, da Sociomuseologia

3 -Museus de partilha social que assentam sobretudo nos novas tecnologias de comunicação, museus sem território formal, mas museus de problemáticas partilhadas: Redes globais, locais de consciência; e por fim;

4- Pensamos também em museus do espetáculo multimédia das indústrias criativas, onde a forma e o brilho das soluções tecnológicas se sobrepõem aos conteúdos que, quando existem,

3 MOUTINHO, M. (2015), "Entre os museus de Foucault e os museus complexos" 
expressam a ideologia dominante. Paradigmas da sustentabilidade ambiental, valores universais da arte, labirintos de arquitetura que consagram relações de poder e o poder da política dominante. São o que chamamos de "Novos Museus Imperiais" forjados em tempos de neoliberalismo: Museu do Amanhã Rio de Janeiro, Museu Guggenheim Bilbau o Louvre do Kuwait, os grandes parques temáticos da industria do lazer.

O mesmo autor reconhece que é cada vez mais difícil imaginar categorias completamente estanques no universo da museologia contemporânea, diz-nos:

"Hoje é impossível imaginar um museu imperial sem programas de inclusão social, ou museus de favela sem coleções de objetos herdados, ou redes sociais sem novas museografias. $E$ todos os conceitos que lhes estão subjacentes aparecem agora como novas formas de heterotopias marcadas pelos seus próprios espaços formais e relacionais onde não é mais a diferença que singulariza, mas antes pelo contrário é na justaposição que encontram a sua essência.

Para todos estes modelos de museus, constroem-se competências profissionais que sustentam novas áreas de formação. Deste ponto de vista a construção de processos dialógicos Freirianos, o manuseamento da computação ubíqua, o planeamento estratégico, a avaliação de públicos, a construção de marcas, o marketing do lazer, são questões que sustentam as diferentes formas que a museologia contemporânea tem vindo a assumir ${ }^{4 "}$

\footnotetext{
4 MOUTINHO, M. (2015), "Entre os museus de Foucault e os museus complexos"
} 
Por si só, diferentes perceções e interpretações do processo de globalização cultural não são suficientes para elucidar a essência das relações sociais de poder que norteia tanto a homogeneização como a diferenciação; mas, sem esse entendimento, os dois processos correm o perigo de serem postos no mesmo nível, sem que se reconheça as vinculações e as hierarquias entre eles.

\section{BIBLIOGRAFIA}

Anderson, B. (2005). Comunidades imaginadas: Reflexões sobre a origem e a expansão do nacionalismo. (Col. Perspectiva do Homem). Lisboa: Edições 70. (Edição original, 1983).

Appadurai, A. (2004). Dimensões Culturais da Globalização: $A$ modernidade sem peias. (Col. Teorema Série Especial/ 58). Lisboa: Ed. Teorema. (Edição original 1996)

Canclini, N. G. (1994). O Património e a cultural e a construção imaginária do nacional. In: Revista do património histórico e artístico nacional/ 23, (pp., 95-115). Rio de Janeiro: IPHAN.

- (1998). Culturas híbridas: Estratégias para entrar e sair da modernidade. Ensaios Latino-Americanos/ 1. (2 2 ed.). São Paulo: EDUS. (Edição original. 1997).

. (1999). Consumidores e cidadãos: conflitos multiculturais da globalização. (4a Edição, 10 reimpressão). Rio: de Janeiro: ED UFRJ (1a edição 1995).

Castells, M (2003). A era da informação: economia e cultura. (Vol. II: O Poder da Identidade). Lisboa: Fundação Calouste Gulbenkian - Serviço de Educação e Bolsas. 
Chagas, M. S. (2002). Memória e poder: dois movimentos. In: Museus e Políticas Culturais, Mário de Souza CHAGAS, \& Myriam Sepúlveda SANTOS, (Orgs.). Cadernos de Sociomuseologia/19, (pp., 35-68). Universidade Lusófona de Humanidades e Tecnologias Centro de Estudos de Sociomuseologia. Lisboa: Edições Lusófona.

Choay, F. (2001). A alegoria do património., São Paulo: Estação Liberdade e Fundação Editora da UNESP. (Edição original, 1992).

Featherstone, M. (1997). O desmanche da cultura: Globalização, pós-modernismo e identidade. São Paulo: Studio Nobel/ Sesc.

Hobsbawm, E. (1998). A questão do nacionalismo. Nações e nacionalismo desde 1780. (Col. História/ 2). Lisboa: Terramar.

Jeudy, H. P. (1990) Memória do Social. Col. Ensaio \& Teoria. Rio de Janeiro: Forense Universitária.

Meneses, U. B. (1992). O Discurso Museológico: um desafio para os museus. A exposição museológica: reflexão sobre pontos críticos na prática contemporânea.,. In: Ciências em Museus, (pp., 87-105). São Paulo: EDUSP.

MOUTINHO, M. (2015), "Entre os museus de Foucault e os museus complexos" In.: Entre os museus de Foucault e os museus complexos, Revista MUSAS Setubal 2014

Santos, M. S. (2002). O pesadelo da amnésia colectiva: um estudo sobre os conceitos de memória, tradição e traço do passado. In: Chagas, M. S. \& Santos, M. S. (Orgs.). Museus e Políticas Culturais, Cadernos de Sociomuseologia/19, (pp., 121-150). Universidade Lusófona de Humanidades e 
Tecnologias. Centro de Estudos de Sociomuseologia. Lisboa: Edições Lusófona.

Santos, B. S. (Org.). (2005). Globalização: fatalidade ou utopia? Col. A Sociedade Portuguesa Perante o Desafio da Globalização/ 1. Direcção Boaventura de Sousa Santos. Porto: Afrontamento. (Edição original, 2001). 